\title{
Single-institution cross-sectional study to evaluate need for information and need for referral to psychooncology care in association with depression in brain tumor patients and their family caregivers
}

Christiane Reinert ${ }^{1}$, Michael Gerken², Katharina Rathberger ${ }^{1}$, Katharina Krueger ${ }^{1}$, Monika Klinkhammer-Schalke², Patricia Lindberg-Scharf ${ }^{2}$, Oliver Koelb| ${ }^{3}$, Martin A. Proescholdt ${ }^{4}$, Markus J. Riemenschneider ${ }^{5}$, Tobias Pukrop ${ }^{6}$, Elisabeth Bumes ${ }^{1}$, Markus Hutterer ${ }^{1,7}$ and Peter Hau ${ }^{1 *}$ (D)

\begin{abstract}
Background: The prognosis of patients with brain tumors is widely varying. Psychooncologic need and depression are high among these patients and their family caregivers. However, the need for counselling and need for referral to psychooncology care is often underestimated.
\end{abstract}

Methods: We performed a single-institution cross-sectional study to evaluate psychooncologic need, depression and information need in both patients and their family caregivers. The Hornheider Screening Instrument (HSI) and the Patient Health Questionnaire (PHQ-9) were used to evaluate psychooncologic need and depression, and a study-specific questionnaire was developed to evaluate information need. Multivariable analyses were performed to detect correlations.

Results: A total of 444 patients and their family caregivers were approached to participate, with a survey completion rate of $35.4 \%$. More than half of the patients and family caregivers were in need for referral to psychooncology care and $31.9 \%$ of patients suffered from clinically relevant depression. In multivariable analysis, psychooncologic need were positively associated with mild (odds ratio, OR, 7.077; 95\% confidence interval, Cl, 2.263-22.137; $p=0.001$ ) or moderate to severe (OR 149.27, 95\% Cl 26.690-737.20; $p<0.001)$ depression. Patient information need was associated with depression (OR 3.007, 95\% Cl 1.175-7.695; $p=0.022$ ).

(Continued on next page)

\footnotetext{
* Correspondence: peter.hau@ukr.de

1 Department of Neurology and Wilhelm Sander-NeuroOncology Unit,

University Hospital Regensburg, Franz-Josef-Strauß-Allee 11,

Universitätsstrasse 84, 93053 Regensburg, Germany

Full list of author information is available at the end of the article
}

C C The Author(s). 2020 Open Access This article is licensed under a Creative Commons Attribution 4.0 International License, which permits use, sharing, adaptation, distribution and reproduction in any medium or format, as long as you give appropriate credit to the original author(s) and the source, provide a link to the Creative Commons licence, and indicate if changes were made. The images or other third party material in this article are included in the article's Creative Commons licence, unless indicated otherwise in a credit line to the material. If material is not included in the article's Creative Commons licence and your intended use is not permitted by statutory regulation or exceeds the permitted use, you will need to obtain permission directly from the copyright holder. To view a copy of this licence, visit http://creativecommons.org/licenses/by/4.0/. The Creative Commons Public Domain Dedication waiver (http://creativecommons.org/publicdomain/zero/1.0/) applies to the data made available in this article, unless otherwise stated in a credit line to the data. 
(Continued from previous page)

Conclusions: Unmet counselling need in brain tumor patients and their family caregivers associate to high

psychooncologic need and depression. Adequate information may decrease the need for referral to

psychooncology care and treatment of depression in these patients. Future studies should further explore these

relations to promote development of supportive structures.

Keywords: Brain tumor, Patient, Family caregiver, Psychooncologic need, Need for referral to psychooncology care, Information need, Depression

\section{Background}

Primary tumors of the central nervous system (CNS) have an average annual age-adjusted incidence of 5.47 per 100,000 population [1]. Brain tumors are a heterogeneous group of diseases that are associated with widely varying prognoses.

Brain tumor patients are a specific population as they often suffer from neurocognitive problems and depression, that may influence need for referral to psychooncology care and information need. A wealth of publications and clinical experience demonstrates that the requirement for patientoriented information, counselling, and need for referral to psychooncology care is high in these patients $[2,3]$. Furthermore, needs and preferences are heterogenous amongst patients and caregivers [4].

Recent publications show that more than half of patients with glioma report distress during their disease course, which partly resolves after active treatment is finished. However, subjects with high distress at diagnosis remain highly distressed at follow-up [3]. Younger age, functional impairment, and concurrent major depression are independently associated with high distress levels. The most frequently reported causes of distress are worry, fatigue, sleep difficulties, and sadness [5].

The supportive needs of brain tumor patients are high and depend on distress and other patient- and diseaserelated factors [6-8]. Family caregivers - who also have high supportive care requirements which persist over time should be included in the supportive setting $[9,10]$. Adequate information is one important component of a supportive structure [11]. Provision of individual information can reduce distress [12] and help patients to cope with their disease $[13,14]$. The quality of life of patients and caregivers depends on coping strategies, which, in turn, are based on support [15].

Previous studies have shown that at least $25-30 \%$ of all cancer patients require referral to psychooncology care. This is particularly true for patients with a poor prognosis $[16,17]$. Referral to psychooncologic care has positive effects in terms of the burden of diagnosis and coping with the disease [18], and may also prolong survival time [19].

Young adults may have different communication and care preferences to older persons [20]. A greater unmet information need is associated with lower overall mental and physical quality of life. In the younger population, almost half of patients report a negative impact of cancer on personal self-control. In this subpopulation, perceived control and unmet information need were independently associated with quality of life [21].

In clinical routine, however, the need for information and need for referral to psychooncology care is often underestimated [22]. In addition, it has not yet been investigated how adequate, patient-centered measures can best be provided for brain tumor patients and their family caregivers.

The aim of this cross-sectional study was to evaluate the relationships between tumor burden and information need in patients with brain tumors and their family caregivers. Using multivariable analyses, known prognostic factors and other potential cofounders were evaluated to detect correlations between psychooncologic need, information need, and depression in patients and family caregivers.

\section{Methods}

\section{Patients and relatives}

This single-center cross-sectional study included all adult and legally competent patients with a World Health Organization (WHO) grade I to IV brain tumor who were treated at the Regensburg Brain Tumor Centre between January 2014 and September 2015. Histologies included astrocytoma, oligoastrocytoma, oligodendroglioma, glioblastoma, ependymoma, primary central nervous system (CNS) lymphoma, and meningioma. Patients and their family caregivers were questioned once at a specific cut off-date (questionnaires mailed 01.09.2015). Patients were undergoing first-line or recurrence treatment with various modalities (surgery, radiotherapy, systemic therapy, experimental therapy) at the time the questionnaire was completed.

The mailed package included one set of questionnaires for the patient and a second set to be passed on to a family caregiver/relative. Patients and caregivers both received the Hornheider Screening Instrument (HSI), Patient Health Questionnaire (PHQ-9) and an in-house brain tumor-specific self-assessment questionnaire. No reminder was sent. All questionnaires returned by the 
end of December 2015 were evaluated. Patients and family caregivers decided whether their data would be stored pseudonymized or in identifiable form. If storage of personalized data was selected, patient information materials were sent or referral to psychooncology care was offered as required on the basis of the returned questionnaire.

Participation was voluntary, and patients and family caregivers could decline to participate. The local ethics committee of the University of Regensburg issued a positive vote on the conduct of this study (number 14101-0291). All procedures were performed according to the ethical standards laid down in the 1964 Declaration of Helsinki and its later amendments. This noninterventional investigation was not registered in a publicity accessible database.

\section{Questionnaires}

We used the Hornheider Screening Instrument (HSI), an established screening tool to sort patients into groups with and without need for referral to psychooncology care, to evaluate psychooncologic need [23]. The data of the patients questionnaires were analyzed via summation of the item scores to a summed score ranging from 0 to 14 , with higher scores indicating an increased psychooncologic need. We defined that a patient required referral to psychooncology care if the summed score was $>3$, and thereby constructed two groups for further evaluation, with a score of $0-3$ and 4-14 [24].

The Patient Health Questionnaire (PHQ-9), a published and broadly used instrument, was used to assess depression [25]. PHQ-9 diagnoses a likely major depression if five or more symptoms of depression occurred on more than half the days of the prior week, and if at least one cardinal symptom is present. The summed score correlates to the extent of depression. In this study, we graded 0-4 points as no depression, 5-9 as mild depression, $10-14$ as moderate depression, and $\geq 15$ points as severe depression and categorized patients into the three groups 0-4, 5-9 and above 10 for further analysis. Values greater or equal to 10 were classified as clinically relevant [26].

Based on frequently asked questions, an in-house brain tumor-specific self-assessment questionnaire, which is available in German language, was developed to evaluate the information approach, information behavior, information level, and information requirements of patients and family caregivers. The questions were tested and adapted in a construction cohort [27] and were later extended to the current population. In the first part of the questionnaire, medical and sociodemographic data such as sex, age, education level, working situation, brain tumor diagnosis, treatment situation, and approach to psychooncology care and social care were collected in a standardized manner. In the second part, participants were asked to describe how and to what extent they wished to be informed about their disease and its treatment. The third part covered five areas of questions on information need (specific question: "On which topics can we currently support you with information?") concerning diagnosis, treatment, living with cancer, additional support, and legal issues, which included brain tumor-specific items. If at least in one of the five topics a support with information was desired, we categorized the patient or caregiver as having information need.

All questionnaires were used in the mother language of patients and family caregivers, German.

\section{Hypotheses, aims and comparison of groups}

Our main hypothesis was that psychooncologic need and depression burden may associate with counselling and information need.

Our primary aim was to identify relationships between psychooncologic need, information need, and depression in patients with primary brain tumors and their caregivers. Secondary aims were to describe the items listed above, to inform counselling of future patients, and to generate hypotheses for further research.

\section{Statistics}

For continuous data, descriptive statistics were applied (SPSS version 25.0; IBM Corp., Armonk, NY, USA) using the mean, median, minimum, maximum, and standard deviation. Categorical data are presented as absolute and relative frequencies. Continuous variables were compared between patients and family caregivers using the $t$-test for normally distributed data and the Mann-Whitney $U$ test for non-normally distributed data. The independence of categorical variables was tested with Pearson's chi-squared test at a significance level of 5\%. In case of small numbers, the Fisher's exact test was applied.

A multivariable binary logistic regression analysis was performed to control for known confounding factors. Known prognostic factors as age, sex, marital status, education level, working situation, WHO grade (grade I or II vs. III vs. IV) [28], tumor status (primary or relapse), time from diagnosis, and treatment status (surgery and radiotherapy vs. chemotherapy vs. follow-up) were corrected for in multivariable analysis. Results were presented as odds ratios (OR) with $95 \%$ confidence intervals $(95 \% \mathrm{CI})$.

Potential sources of bias were addressed by approaching a consecutive series of patients with predefined characteristics, by approaching them without preselection, by processing all available data in a pseudonymized way, and by using statistical methods that are suited to minimize bias. 


\section{Results}

\section{Patients and family caregivers}

In total, 444 patients were approached to fill in the questionnaire. For each patient, a questionnaire for a family caregiver was added to the mailed package, which could be delivered to any relative within the family. Of the 444 patients approached, 172 (38.7\%) took part in the survey. Within the participating patient cohort, 142 family caregivers $(82.6 \%)$ also responded. Details are shown in the CONSORT diagram (Additional file 1 [27];). Patient and family caregiver characteristics are outlined in Table 1.

Of the participating patients, $92(43.5 \%)$ were in firstline treatment and 80 patients $(46.5 \%)$ were in relapse. Regarding their tumors, $38.4 \%$ of patients had WHO grade I or II, $30.2 \%$ grade III, and $31.4 \%$ had grade IV tumors. Of all patients, $75.0 \%(n=129)$ were living in a partnership at the time of the survey and $76.1 \%(n=$ 108) of the involved relatives were partners or spouses. Three $(0.7 \%)$ patients received assistance from relatives or medical staff in completing the questionnaires due to difficulties with the German language.

\section{Access to psychooncologic care}

At the Regensburg Brain Tumor Centre, $43.0 \%$ of patients $(n=74)$ and $30.3 \%$ of relatives $(n=43 ; p=0.021)$ had had contact with psychooncology care during an out- or in-patient visit to the hospital. Offers of referral to psychooncology care were accepted by a comparable number of young and elderly patients $(p=0.728)$, with a contact rate of $41.9 \%$ among patients aged $\leq 35$ years years $(n=13), 46.7 \%$ for $36-50$ years $(n=21), 44.1 \%$ for 51-65 years $(n=26)$, and $56.0 \%$ among patients $>65$ years of age $(n=14)$. With increasing tumor grade, contact to the psychooncology care showed a trend toward increasing $(p=0.054)$, from $36.1 \%$ in $\mathrm{WHO}$ grade $\mathrm{I} / \mathrm{II}$ $(n=22)$ to $46.0 \%$ in WHO grade III $(n=23)$ and $59.2 \%$ in WHO grade IV $(n=29)$. Contact with psychooncologists did not vary significantly $(p=0.827)$ with education level (low: $43.5 \%, n=10$; middle: $49.4 \%, n=41$; high: $45.1 \%, n=23)$.

\section{Psychooncologic need}

Psychooncologic need was high among patients and relatives according to the HSI. More than half of the respondents $(53.0 \%$ of patients, $n=85$; and $58.2 \%$ of relatives, $n=78 ; p=0.382$ ) had a psychooncologic need (Additional file $2 \mathrm{a})$ and $47.1 \%$ of patients $(n=81)$ answered that someone in their family is affected by the illness.

In comparison to their pre-illness state, 9.3\% of patients $(n=16)$ and $19.7 \%$ of relatives $(n=28)$ had fewer social contacts to talk to about their fears and worries during the disease course ( $p=0.047$, Additional file $2 \mathrm{~b}$ ). Significantly less time to rest during the day was reported by $22.1 \%$ of patients $(n=38)$ and $35.9 \%$ of relatives $(n=51 ; p=0.016)$.

Comparing mean HSI scores, patients' psychooncologic need was dependent on age group, with lower need in the group aged $\leq 35$ years (mean HSI score: 3.10 , Additional file 3) and a significant peak in the 51-65 years age group (mean HSI score: 4.58, $p=0.027$ ). Psychooncologic need was higher in patients with highly malignant tumors (mean HSI score: 4.40). Patients with low education levels tended to have a higher psychooncologic need ( $n=24$, mean HSI score: 4.58 ) when compared to patients with a high education level $(n=54$, mean HSI score: $3.83 ; p=0.534)$.

Patients had a significantly higher psychooncologic need (HSI: 4+ vs. 0-3, Additional file 4) while receiving chemotherapy (yes $68.2 \%$ vs. no $56.0 \%$ ) than in phases without treatment (yes $20.0 \%$ vs. no $13.3 \%$; $p=0.03$ ). Patients felt significantly less adequately informed about their diagnosis ( 83.1 vs. $95.6 \%, p=0.011$ ) and treatment (81.7 vs. $94.4 \%, p=0.016$ ) if the psychooncologic need was high. The most significant uneven distribution was observed for depression: among patients with a high psychooncologic need, the rate of moderately or severely depressed patients was $58.8 \%$ compared to $5.3 \%$ in the group without psychooncologic need $(p<0.001)$. No significant relationship was seen with other factors such as sex, age, marital status, education level, working situation, WHO grade, tumor status, and time from diagnosis.

In the univariable and multivariable regression analyses, psychooncologic need was not significantly related to any of the categories investigated except for depression levels. Here, patients with mild (OR 7.077, 95\% CI $2.263-22.137 ; p=0.001$ ) and moderate to severe (OR 149.27; 95\% CI 26.690-737.20; $p<0.001)$ depression levels had significantly higher psychooncologic need as opposed to patients with no to minimal depression (multivariable regression, Table 2; Fig. 1a).

\section{Depression burden}

The depression burden was high in our analysis (Additional file 5). The result of the summed score analysis showed mild to severe depressive syndrome in $65.0 \%$ of patients ( $n=112$, mean score 10.6$)$ and $66.9 \%$ of caregivers $(n=95$, mean score 10.9). Clinically relevant scores $>10$ were observed for $31.9 \%(n=55)$ of patients and $28.9 \%(n=41)$ of patients' caregivers. In the categorical assessment, $15.7 \%$ of patients $(n=27)$ and $19.0 \%$ of relatives $(n=27)$ screened positive for major depression, with mean scores of 17.4 and 18.3 , respectively. Suicidal thoughts on several days were declared by 28 patients and 17 relatives, including three in each group who experienced these thoughts on more than half of the days and four patients and six caregivers who experienced 
Table 1 Characteristics of patients and family caregivers. Distribution of relevant patient characteristics. Significant differences are shown in bold

\begin{tabular}{|c|c|c|c|c|c|c|}
\hline \multirow{2}{*}{$\begin{array}{l}\text { Variable } \\
\text { Sex }\end{array}$} & \multirow{2}{*}{$\begin{array}{l}\text { Code } \\
\text { Male }\end{array}$} & \multicolumn{2}{|c|}{$\begin{array}{l}\text { Patients } \\
N=172\end{array}$} & \multicolumn{2}{|c|}{$\begin{array}{l}\text { Family caregivers } \\
N=142\end{array}$} & \multirow{2}{*}{$\begin{array}{l}\begin{array}{l}\text { Chi-squar } \\
\text { ( } \boldsymbol{p} \text {-value) }\end{array} \\
0.446\end{array}$} \\
\hline & & 75 & $43.6 \%$ & 66 & $46.5 \%$ & \\
\hline & Female & 97 & $56.4 \%$ & 74 & $52.1 \%$ & \\
\hline & Unknown & 0 & $0 \%$ & 2 & $1.4 \%$ & \\
\hline Age (mean) & & \multicolumn{2}{|c|}{$\begin{array}{l}51.4 \text { years } \\
{[\min 20 / \max 84]}\end{array}$} & \multicolumn{2}{|c|}{$\begin{array}{l}53.5 \text { years } \\
\text { [min } 19 / \max 82]\end{array}$} & - \\
\hline \multirow[t]{5}{*}{ Age categories (years) } & $\leq 35$ & 31 & $18.0 \%$ & 14 & $9.9 \%$ & 0.107 \\
\hline & $36-50$ & 45 & $26.2 \%$ & 39 & $27.5 \%$ & \\
\hline & $51-65$ & 68 & $39.5 \%$ & 61 & $43.0 \%$ & \\
\hline & $>65$ & 28 & $16.3 \%$ & 25 & $17.6 \%$ & \\
\hline & Unknown & 0 & $0 \%$ & 3 & $2.1 \%$ & \\
\hline \multirow[t]{3}{*}{ Marital status } & Single & 41 & $23.8 \%$ & 2 & $1.4 \%$ & $<0.001$ \\
\hline & Living in a partnership & 129 & $75.0 \%$ & 104 & $73.2 \%$ & \\
\hline & Unknown & 2 & $1.2 \%$ & 36 & $25.4 \%$ & \\
\hline \multirow[t]{4}{*}{ Relationship } & Partner & & & 108 & $76.1 \%$ & \\
\hline & Child & & & 11 & $7.7 \%$ & \\
\hline & Parent & & & 18 & $12.7 \%$ & \\
\hline & Close relative & & & 5 & $3.5 \%$ & \\
\hline \multirow[t]{11}{*}{ Education level } & Low education level & & & & & 0.820 \\
\hline & No educational qualification & 2 & $1.2 \%$ & 2 & $1.4 \%$ & \\
\hline & Basic school qualification & 23 & $13.4 \%$ & 22 & $15.5 \%$ & \\
\hline & Medium education level & & & & & \\
\hline & Secondary school certificate & 21 & $12.2 \%$ & 20 & $4.1 \%$ & \\
\hline & Completed apprenticeship & 68 & $39.5 \%$ & 46 & $32.4 \%$ & \\
\hline & High education level & & & & & \\
\hline & High school graduation & 15 & $8.7 \%$ & 6 & $4.2 \%$ & \\
\hline & Master craftsman's diploma & 12 & $7.0 \%$ & 13 & $9.2 \%$ & \\
\hline & University degree & 28 & $16.3 \%$ & 30 & $21.1 \%$ & \\
\hline & Unknown & 3 & $1.7 \%$ & 3 & $2.1 \%$ & \\
\hline \multirow[t]{5}{*}{ Work situation } & Full time & 40 & $23.3 \%$ & 60 & $42.3 \%$ & $<0.001$ \\
\hline & Part time & 23 & $13.4 \%$ & 26 & $18.3 \%$ & \\
\hline & Sick leave & 15 & $8.7 \%$ & 1 & $0.7 \%$ & \\
\hline & Retired & 75 & $43.6 \%$ & 41 & $28.9 \%$ & \\
\hline & Other & 19 & $11.1 \%$ & 14 & $9.8 \%$ & \\
\hline \multirow[t]{6}{*}{ Diagnosis } & Glioblastoma & 34 & $19.8 \%$ & - & - & - \\
\hline & Astrocytoma & 48 & $27.9 \%$ & & & \\
\hline & Oligoastrocytoma & 31 & $18.0 \%$ & & & \\
\hline & /Oligodendroglioma & & & & & \\
\hline & Meningioma & 19 & $11.0 \%$ & & & \\
\hline & Other & 40 & $23 . \%$ & & & \\
\hline \multirow[t]{3}{*}{ Tumour grading } & WHO I/II ("Iow grade") & 66 & $38.4 \%$ & - & - & - \\
\hline & WHO III ("intermediate") & 52 & $30.2 \%$ & & & \\
\hline & WHO IV ("high grade") & 54 & $31.4 \%$ & & & \\
\hline
\end{tabular}


Table 2 Multivariable regression analysis of patients' psychooncologic need. Results of univariable and multivariable binary logistic regression analysis on psychooncologic need (Hornheider score 4+ vs 0-3; $N=160$, missings not shown; significant differences are shown in bold)

\begin{tabular}{|c|c|c|c|c|c|c|c|c|c|}
\hline & & \multicolumn{4}{|c|}{ Univariable } & \multicolumn{4}{|c|}{ Multivariable } \\
\hline & & \multirow[t]{2}{*}{$p$-value } & \multirow{2}{*}{$\begin{array}{l}\text { odds } \\
\text { ratio }\end{array}$} & \multicolumn{2}{|l|}{$95 \% \mathrm{Cl}$} & \multirow[t]{2}{*}{$p$-value } & \multirow{2}{*}{$\begin{array}{l}\text { odds } \\
\text { ratio }\end{array}$} & \multicolumn{2}{|l|}{$95 \% \mathrm{Cl}$} \\
\hline & & & & lower & higher & & & lower & higher \\
\hline \multirow[t]{2}{*}{ Sex } & Male & & 1.000 & & & & 1.000 & & \\
\hline & Female & 0.317 & 1.379 & 0.735 & 2.587 & 0.422 & 1.501 & 0.556 & 4.051 \\
\hline \multirow[t]{4}{*}{ Age } & $\leq 35$ & & 1.000 & & & & 1.000 & & \\
\hline & $36-50$ & 0.391 & 1.514 & 0.587 & 3.906 & 0.927 & 0.937 & 0.232 & 3.791 \\
\hline & $51-65$ & 0.172 & 1.840 & 0.768 & 4.413 & 0.771 & 0.803 & 0.183 & 3.513 \\
\hline & $>65$ & 0.626 & 1.308 & 0.445 & 3.842 & 0.943 & 0.922 & 0.101 & 8.399 \\
\hline \multirow[t]{2}{*}{ Marital status } & Single & & 1.000 & & & & 1.000 & & \\
\hline & Partnership & 0.989 & 0.995 & 0.479 & 2.066 & 0.511 & 0.676 & 0.210 & 2.171 \\
\hline \multirow[t]{3}{*}{ Education level } & Low & & 1.000 & & & & & & \\
\hline & Middle & 0.616 & 0.789 & 0.314 & 1.986 & 0.928 & 0.932 & 0.200 & 4.334 \\
\hline & High & 0.497 & 0.714 & 0.270 & 1.886 & 0.460 & 1.844 & 0.363 & 9.356 \\
\hline \multirow[t]{4}{*}{ Working situation } & Full time & & 1.000 & & & & 1.000 & & \\
\hline & Part time & 0.380 & 1.600 & 0.561 & 4.567 & 0.985 & 1.017 & 0.176 & 5.890 \\
\hline & Sick leave & 0.402 & 1.676 & 0.501 & 5.611 & 0.532 & 0.539 & 0.078 & 3.737 \\
\hline & Retired & 0.102 & 1.972 & 0.874 & 4.449 & 0.758 & 1.280 & 0.266 & 6.171 \\
\hline \multirow[t]{3}{*}{ WHO grade } & WHO I/II & & 1.000 & & & & 1.000 & & \\
\hline & WHO III & 0.686 & 0.853 & 0.394 & 1.844 & 0.837 & 0.888 & 0.288 & 2.740 \\
\hline & WHO IV & 0.936 & 1.031 & 0.495 & 2.146 & 0.311 & 0.503 & 0.133 & 1.899 \\
\hline \multirow[t]{2}{*}{ Tumor status } & Primary diagnosis & & 1.000 & & & & 1.000 & & \\
\hline & Relapse & 0.827 & 1.072 & 0.575 & 1.998 & 0.384 & 0.607 & 0.197 & 1.869 \\
\hline \multirow[t]{4}{*}{ Time from diagnosis/relapse (years) } & $<1.0$ & & 1.000 & & & & 1.000 & & \\
\hline & $1.0-4.9$ & 0.339 & 0.690 & 0.322 & 1.478 & 0.485 & 0.611 & 0.153 & 2.438 \\
\hline & $5.0+$ & 0.560 & 0.762 & 0.306 & 1.900 & 0.172 & 0.344 & 0.074 & 1.592 \\
\hline & ns & 0.188 & 0.500 & 0.178 & 1.405 & 0.121 & 0.304 & 0.067 & 1.369 \\
\hline \multirow[t]{4}{*}{ Treatment status } & Chemotherapy & & 1.000 & & & & 1.000 & & \\
\hline & Radiotherapy/surgery & 0.342 & 0.294 & 0.024 & 3.671 & 0.690 & 0.251 & 0.000 & 221.94 \\
\hline & Follow-up & 0.642 & 0.812 & 0.338 & 1.951 & 0.796 & 1.234 & 0.250 & 6.092 \\
\hline & No treatment & 0.014 & 0.252 & 0.084 & 0.761 & 0.123 & 0.243 & 0.040 & 1.468 \\
\hline \multirow[t]{2}{*}{ Information level (general) } & Informed & & 1.000 & & & & 1.000 & & \\
\hline & Not informed & 0.067 & 4.318 & 0.901 & 20.678 & 0.576 & 0.549 & 0.067 & 4.496 \\
\hline \multirow[t]{3}{*}{ Depression (PHQ-9 score) } & No/minimal (0-4) & & 1.000 & & & & 1.000 & & \\
\hline & Mild (5-9) & $<0.001$ & 5.000 & 2.035 & 12.282 & 0.001 & 7.077 & 2.263 & 22.137 \\
\hline & Moderate/severe (10+) & $<0.001$ & 62.500 & 18.001 & 217.00 & $<0.001$ & 140.27 & 26.690 & 737.20 \\
\hline
\end{tabular}

these thoughts nearly every day. If patients had consented to being contacted in these cases, they were advised to visit a psychiatrist or psychooncologist.

Mean depression levels significantly increased with age (Additional file 6). Patients $\leq 35$ years $(n=28)$ had the lowest depression levels $($ mean $=6.27)$ when compared to patients aged $51-65(n=64$, mean $=9.28, p=0.017)$ or $>65$ years $(n=25$, mean $=9.12, p=0.060)$. Although patients with WHO grade I-II (low-grade) tumors $(n=57)$ declared no diagnosis or treatment burden, the mean depression level $($ mean $=8.47)$ tended to be higher than in the patient group with WHO grade III tumors $(n=47$, mean $=7.09 ; p>0.05)$. Patients with WHO grade IV (high-grade) tumors $(n=51)$ had a significantly higher mean depression level $($ mean $=$ 9.57; $p=0.024$ ) compared to WHO grade III. 


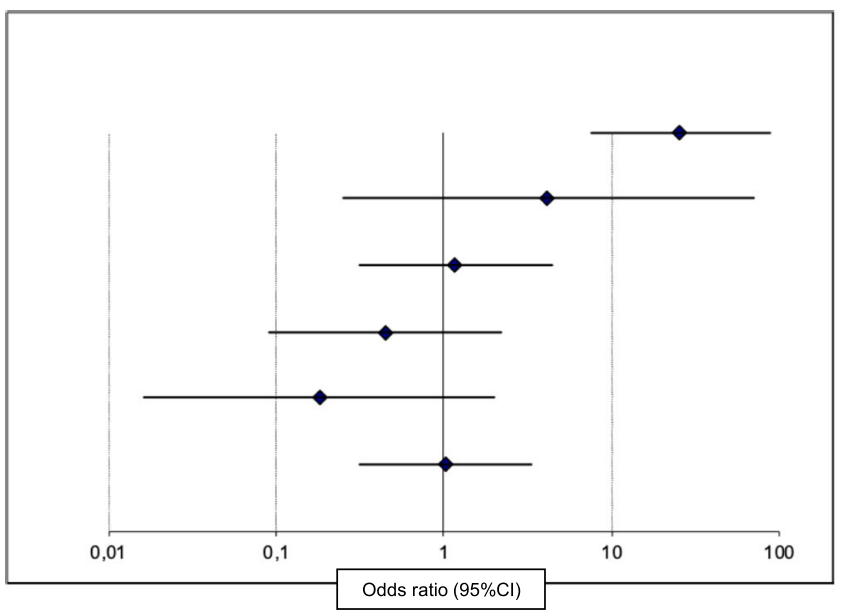

Psychooncologic need

Low information status

WHO grade IV

High education level

Age $>65$ years

Female sex

b (Psychooncologic need)

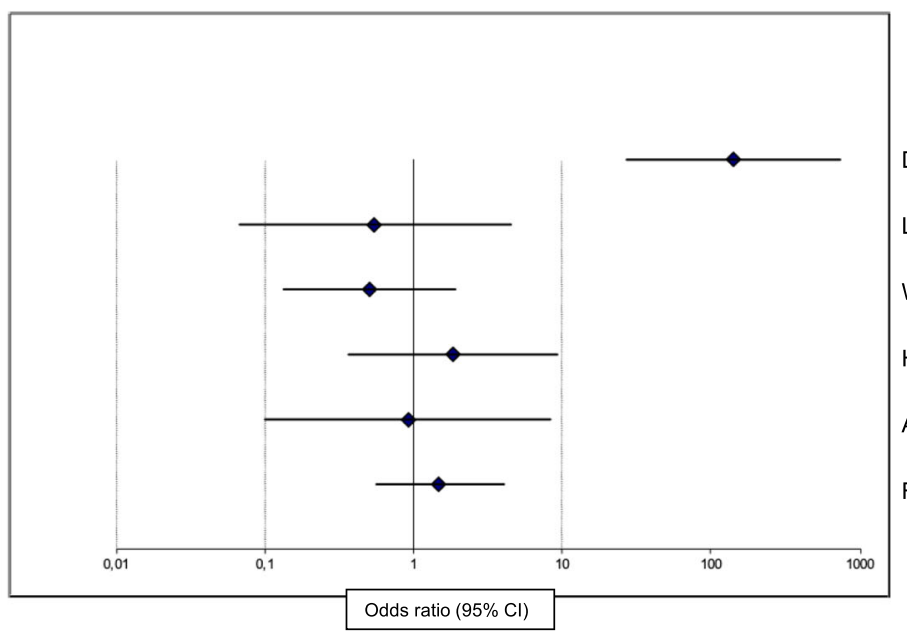

Depression

Low information status

WHO grade IV

High education level

Age $>65$ years

Female sex

(Information need)

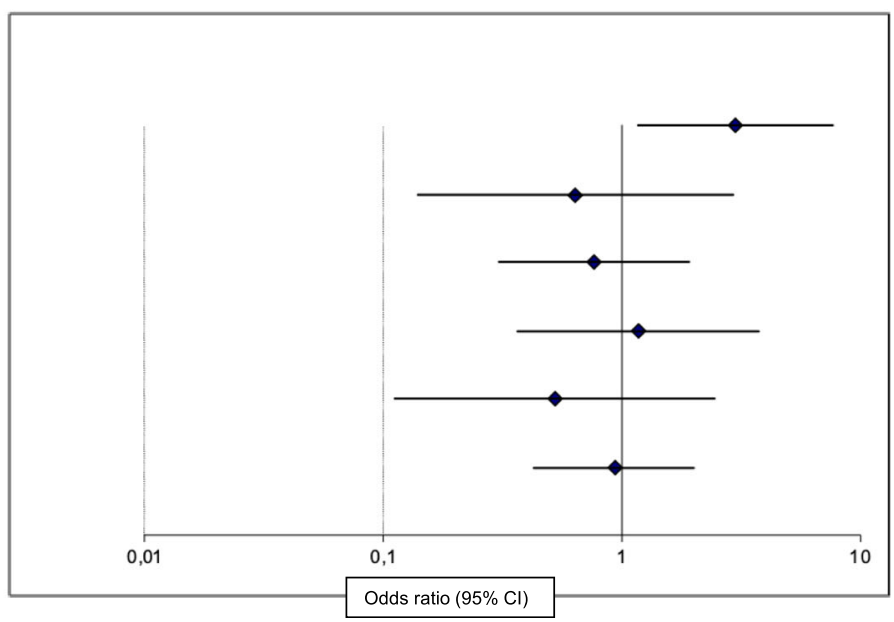

Depression

Low information status

WHO grade IV

High education level

Age $>65$ years

Female sex 


\begin{abstract}
Fig. 1 Impact of patient characteristics on depression, psychooncologic need, and information need. a: Multivariable binary logistic regression analysis of depression, showing the odds ratios of mild to severe vs no to minimal depression in relation to psychooncologic need, low information status, high WHO grade, high education level, higher age and female sex. A mild to severe depression relates significantly to a higher psychooncologic need. b: Multivariable binary logistic regression analysis of psychooncologic need, showing the odds ratios of psychooncologic need in relation to mild to severe depression, low information status, high WHO grade, high education level, higher age and female sex . A higher psychooncologic need relates significantly to a mild to sever depression. c: Multivariable binary logistic regression analysis of information need, showing the odds ratios of information need in relation to mild to severe depression, low information status, high WHO grade, high education level, higher age and female sex. Higher information need relates significantly to a mild to severe depression
\end{abstract}

The patient group with a low education level $(n=21)$ had significantly higher summed depression scores (mean $=11.48)$ when compared to patients with a medium $(n=84$, mean $=8.18 ; p=0.012)$ or high education level $(n=47$, mean $=7.38 ; p=0.004)$.

The mean depression level was independent of disease status, namely first diagnosis or progression (mean $=8.6$, $n=81$ at first diagnosis vs. mean $=8.3, n=74$ with progressive disease; $p=0.711$ ).

Both the distribution of patients' characteristics according to depression (Additional file 7) and the results of univariable and multivariable logistic regression analyses show dependencies comparable to the relationships seen for psychooncologic need (Table 3, Fig. 1b): no significant dependency on sex, age, marital status, education level, working situation, WHO grade, tumor status, or time from diagnosis was observed.

The rate of treated patients was significantly higher among those with mild to severe depression (score of $5+$ derived from PHQ-9) compared to patients with no to minimal depression (score 0-4, $p=0.018$; Additional file 7). The number of patients who felt sufficiently informed about diagnosis and treatment was significantly lower among patients with mild or moderate to severe depression (diagnosis: 85.3 vs. $98.3 \%, p=0.008$; treatment: 83.2 vs. $94.9 \%, p=0.029)$ than in patients with no or minimal depression. The proportion of patients with psychooncologic need was with $71.7 \%$ significantly higher among patients with mild to severe depression as opposed to $16.7 \%$ in patients with no or minimal depression $(p<0.001)$.

The observed relationships were confirmed by univariable logistic binary regression. Only the psychooncologic need continued to be significantly related to depression after risk adjustment by means of multivariable regression (Table 3, Fig. 1b), which corresponds to the results from regression on psychooncologic need.

\section{Information need}

\section{Comparison of patients and relatives}

In our analysis, $41.5 \%$ of family caregivers $(n=59)$ did not feel sufficiently informed about the disease and its treatment, which was comparable to the information level in patients $(38.4 \%, n=66 ; p=0.602)$.

More than half of the interviewed patients $(59.9 \% ; n=$ 103 ) and a significantly higher proportion of family caregivers $(72.5 \% ; n=103 ; p=0.019)$ wished to be fully informed about the cancer disease. The remaining participants wished to receive partial information in different extent. At the time of the survey, 63.4\% $(n=$ 109) of patients and $66.2 \%$ of relatives $(n=94 ; p=$ 0.354) had sought and obtained information on cancer-specific topics, with a clear preference for information on treatment and diagnosis. Concerning psychologic distress, $15.7 \%$ of patients $(n=27)$ and $16.2 \%(n=23 ; p=0.904)$ of family caregivers aimed to be informed on referral to psychooncology care (21.5\%: $n=37$ ) and sought support for psychological stress caused by the diagnosis $(30.3 \% ; n=43 ; p=$ $0.070)$. In addition, $2.1 \%(n=3)$ of the family caregivers had looked for information helplines.

The majority of patients $(87.8 \% ; n=151)$ and family caregivers $(78.2 \% ; n=111)$ felt adequately informed about their diagnosis and $84.3 \%(n=145)$ of patients and $78.2 \%(n=111)$ of relatives felt adequately informed about treatment. The number of family caregivers who did not feel adequately informed about the diagnosis or treatment of their sick family member was considerable, at $19.7(n=28)$ and 20.4\% $(n=29)$, respectively. Patients who had a greater need for information tended to have a more distinctive information-seeking behavior than patients who preferred to leave the decisions to their physicians $(p=0.057)$.

\section{Patients' information need}

From the distribution of patient characteristics depicted in Additional file 8 and the univariable and multivariable regression analysis (Table 4, Fig. 1c), only tendencies toward relationships to levels of patients' information need can be derived.

The only significant correlation was an increase in information need with increasing grades of depression not for mild (OR 2.004, 95\% CI 0.848-4.734; $p=0.113$ ), but for moderate to severe (OR 3.007, 95\% CI 1.175-7.695; $p=0.022$ ) depression vs. no or minimal depression. Furthermore, a non-significant decrease of information need with younger age, fewer therapies, and time from diagnosis or relapse was observed. Similarly, the small increase in information need with higher education level and living in a partnership did not reach significance. No dependency on the status of sufficient information was observed. 
Table 3 Results of univariable and multivariable binary logistic regression analysis on depression, yes vs. no according to PHQ-9 score (depression yes or no. 5+ vs. 0-4; $N=160$, missings not shown; significant differences are shown in bold)

\begin{tabular}{|c|c|c|c|c|c|c|c|c|c|}
\hline & & \multicolumn{4}{|c|}{ Univariable } & \multicolumn{4}{|c|}{ Multivariable } \\
\hline & & \multirow[t]{2}{*}{$p$-value } & \multirow{2}{*}{$\begin{array}{l}\text { odds } \\
\text { ratio }\end{array}$} & \multicolumn{2}{|l|}{$95 \% \mathrm{Cl}$} & \multirow[t]{2}{*}{$p$-value } & \multirow{2}{*}{$\begin{array}{l}\text { odds } \\
\text { ratio }\end{array}$} & \multicolumn{2}{|c|}{$95 \% \mathrm{Cl}$} \\
\hline & & & & lower & higher & & & lower & higher \\
\hline \multirow[t]{2}{*}{ Sex } & Male & & 1.000 & & & & 1.000 & & \\
\hline & Female & 0.787 & 1.091 & 0.580 & 2.051 & 0.963 & 1.028 & 0.316 & 3.347 \\
\hline \multirow[t]{4}{*}{ Age } & $\leq 35$ & & 1.000 & & & & 1.000 & & \\
\hline & $36-50$ & 0.298 & 1.647 & 0.643 & 4.218 & 0.089 & 3.530 & 0.824 & 15.129 \\
\hline & $51-65$ & 0.129 & 1.976 & 0.821 & 4.760 & 0.727 & 1.304 & 0.294 & 5.779 \\
\hline & $>65$ & 0.649 & 1.273 & 0.451 & 3.590 & 0.163 & 0.181 & 0.016 & 2.003 \\
\hline \multirow[t]{2}{*}{ Marital status } & Single & & 1.000 & & & & 1.000 & & \\
\hline & Partnership & 0.843 & 1.077 & 0.518 & 2.238 & 0.571 & 1.446 & 0.404 & 5.175 \\
\hline \multirow[t]{3}{*}{ Education level } & Low & & 1.000 & & & & 1.000 & & \\
\hline & Middle & 0.873 & 0.925 & 0.359 & 2.389 & 0.801 & 1.214 & 0.269 & 5.473 \\
\hline & High & 0.594 & 0.762 & 0.280 & 2.073 & 0.320 & 0.449 & 0.092 & 2.181 \\
\hline \multirow[t]{4}{*}{ Working situation } & Full time & & 1.000 & & & & 1.000 & & \\
\hline & Part time & 0.406 & 1.556 & 0.549 & 4.409 & 0.443 & 2.347 & 0.266 & 20.743 \\
\hline & Sick leave & 0.128 & 2.750 & 0.748 & 10.105 & 0.096 & 4.717 & 0.759 & 29.298 \\
\hline & Retired & 0.009 & 2.947 & 1.312 & 6.621 & 0.097 & 0.158 & 0.018 & 1.394 \\
\hline \multirow[t]{3}{*}{ WHO grade } & WHO I/II & & 1.000 & & & & 1.000 & & \\
\hline & WHO III & 0.881 & 1.059 & 0.499 & 2.247 & 0.620 & 0.724 & 0.201 & 2.601 \\
\hline & WHO IV & 0.344 & 1.448 & 0.672 & 3.119 & 0.815 & 1.171 & 0.312 & 4.401 \\
\hline \multirow[t]{2}{*}{ Tumor status } & Primary diagnosis & & 1.000 & & & & 1.000 & & \\
\hline & Relapse & 0.117 & 1.667 & 0.880 & 3.158 & 0.567 & 1.416 & 0.430 & 4.664 \\
\hline \multirow[t]{4}{*}{ Time from diagnosis/relapse (years) } & $<1.0$ & & 1.000 & & & & 1.000 & & \\
\hline & $1.0-4.9$ & 0.465 & 0.750 & 0.346 & 1.624 & 0.584 & 1.494 & 0.355 & 6.289 \\
\hline & $5.0+$ & 0.754 & 1.168 & 0.442 & 3.086 & 0.109 & 3.759 & 0.745 & 18.977 \\
\hline & ns & 0.315 & 0.594 & 0.215 & 1.639 & 0.887 & 1.123 & 0.226 & 5.586 \\
\hline \multirow[t]{4}{*}{ Treatment status } & Chemotherapy & & 1.000 & & & & 1.000 & & \\
\hline & Radiotherapy/surgery & 0.093 & 0.109 & 0.008 & 1.446 & 0.099 & 0.060 & 0.002 & 1.690 \\
\hline & Follow-up & 0.132 & 0.447 & 0.157 & 1.275 & 0.115 & 0.238 & 0.040 & 1.418 \\
\hline & No treatment & 0.006 & 0.193 & 0.059 & 0.628 & 0.344 & 0.394 & 0.057 & 2.715 \\
\hline \multirow[t]{2}{*}{ Information level (diagnosis) } & Informed & & 1.000 & & & & 1.000 & & \\
\hline & Not informed & 0.028 & 9.978 & 1.289 & 77.259 & 0.316 & 4.200 & 0.254 & 69.436 \\
\hline \multirow[t]{2}{*}{ Information level (treatment) } & Informed & & 1.000 & & & & 1.000 & & \\
\hline & Not informed & 0.040 & 3.775 & 1.063 & 13.405 & 0.756 & 1.416 & 0.158 & 12.666 \\
\hline \multirow[t]{2}{*}{ Psychooncologic need } & No $(0-3)$ & & 1.000 & & & & 1.000 & & \\
\hline & Yes (4+) & $<0.001$ & 12.667 & 5.517 & 29.082 & $<0.001$ & 25.581 & 7.501 & 87.236 \\
\hline
\end{tabular}

\section{Discussion}

This study evaluated information need, psychooncologic need, need for referral to psychooncology care and depression in a large cohort of brain tumor patients and their family caregivers in conjunction with a number of potential confounding factors. The primary aim was to evaluate correlations between psychooncologic need, information need, and depression among patients with brain tumors and their family caregivers.

Patients with brain tumors are of specific interest, as they often suffer from neurocognitive problems and depression, that may influence psychooncologic and information need. In several publications, the need for referral to psychooncology care seems to be higher in patients with primary brain tumors 
Table 4 Multivariable regression analysis of patient information need. Results of univariable and multivariable binary logistic regression analysis on patients' information need ( $N=172$, missings not shown; significant differences are shown in bold)

\begin{tabular}{|c|c|c|c|c|c|c|c|c|c|}
\hline & & \multicolumn{4}{|c|}{ Univariable } & \multicolumn{4}{|c|}{ Multivariable } \\
\hline & & \multirow[t]{2}{*}{$p$-value } & \multirow{2}{*}{$\begin{array}{l}\text { odds } \\
\text { ratio }\end{array}$} & \multicolumn{2}{|l|}{$95 \% \mathrm{Cl}$} & \multirow[t]{2}{*}{$p$-value } & \multirow{2}{*}{$\begin{array}{l}\text { odds } \\
\text { ratio }\end{array}$} & \multicolumn{2}{|l|}{$95 \% \mathrm{Cl}$} \\
\hline & & & & lower & higher & & & lower & higher \\
\hline \multirow[t]{2}{*}{ Sex } & Male & & 1.000 & & & & 1.000 & & \\
\hline & Female & 0.827 & 1.070 & 0.582 & 1.966 & 0.850 & 0.929 & 0.432 & 1.997 \\
\hline \multirow[t]{4}{*}{ Age } & $\leq 35$ & & 1.000 & & & & 1.000 & & \\
\hline & $36-50$ & 0.374 & 0.659 & 0.263 & 1.653 & 0.336 & 0.601 & 0.213 & 1.696 \\
\hline & $51-65$ & 0.394 & 0.690 & 0.294 & 1.620 & 0.577 & 0.740 & 0.257 & 2.131 \\
\hline & $>65$ & 0.022 & 0.275 & 0.090 & 0.833 & 0.409 & 0.521 & 0.111 & 2.447 \\
\hline \multirow[t]{2}{*}{ Marital status } & Single & & 1.000 & & & & 1.000 & & \\
\hline & In partnership & 0.505 & 1.276 & 0.623 & 2.614 & 0.530 & 1.314 & 0.561 & 3.077 \\
\hline \multirow[t]{3}{*}{ Education level } & Low & & 1.000 & & & & & & \\
\hline & Middle & 0.809 & 1.118 & 0.453 & 2.759 & 0.706 & 1.230 & 0.421 & 3.595 \\
\hline & High & 0.545 & 1.345 & 0.515 & 3.510 & 0.786 & 1.175 & 0.367 & 3.768 \\
\hline \multirow[t]{4}{*}{ Working situation } & Full time & & 1.000 & & & & 1.000 & & \\
\hline & Part time & 0.758 & 0.850 & 0.303 & 2.386 & 0.655 & 0.749 & 0.211 & 2.661 \\
\hline & Sick leave & 0.210 & 2.211 & 0.640 & 7.639 & 0.617 & 1.459 & 0.331 & 6.433 \\
\hline & Retired & 0.181 & 0.586 & 0.268 & 1.282 & 0.265 & 0.505 & 0.152 & 1.680 \\
\hline \multirow[t]{3}{*}{ WHO grade } & WHO I/II & & 1.000 & & & & 1.000 & & \\
\hline & WHO III & 0.540 & 1.257 & 0.605 & 2.610 & 0.697 & 1.186 & 0.504 & 2.789 \\
\hline & WHO IV & 0.852 & 0.933 & 0.450 & 1.936 & 0.570 & 0.765 & 0.303 & 1.928 \\
\hline \multirow[t]{2}{*}{ Tumor status } & Primary diagnosis & & 1.000 & & & & 1.000 & & \\
\hline & Relapse & 0.116 & 1.629 & 0.887 & 2.990 & 0.470 & 1.347 & 0.601 & 3.022 \\
\hline \multirow[t]{4}{*}{ Time from diagnosis/relapse (years) } & $<1.0$ & & 1.000 & & & & 1.000 & & \\
\hline & $1.0-4.9$ & 0.182 & 0.605 & 0.290 & 1.264 & 0.617 & 0.771 & 0.279 & 2.132 \\
\hline & $5.0+$ & 0.071 & 0.430 & 0.172 & 1.074 & 0.147 & 0.413 & 0.125 & 1.363 \\
\hline & ns & 0.113 & 0.438 & 0.158 & 1.215 & 0.339 & 0.554 & 0.165 & 1.860 \\
\hline \multirow[t]{4}{*}{ Treatment status } & Chemotherapy & & 1.000 & & & & 1.000 & & \\
\hline & Radiotherapy/surgery & 0.752 & 1.500 & 0.121 & 18.540 & 0.749 & 1.575 & 0.098 & 25.401 \\
\hline & Follow-up & 0.076 & 0.466 & 0.200 & 1.083 & 0.538 & 0.684 & 0.204 & 2.291 \\
\hline & No treatment & 0.430 & 0.667 & 0.244 & 1.825 & 0.629 & 1.403 & 0.356 & 5.524 \\
\hline \multirow[t]{2}{*}{ Information level (general) } & Informed & & 1.000 & & & & 1.000 & & \\
\hline & Not informed & 0.923 & 1.063 & 0.311 & 3.629 & 0.567 & 0.639 & 0.138 & 2.958 \\
\hline \multirow[t]{3}{*}{ Depression (PHQ-9 score) } & No/minimal (0-4) & & 1.000 & & & & 1.000 & & \\
\hline & Mild (5-9) & 0.243 & 1.558 & 0.740 & 3.277 & 0.113 & 2.004 & 0.848 & 4.734 \\
\hline & Moderate/severe (10+) & 0.086 & 1.926 & 0.911 & 4.073 & 0.022 & 3.007 & 1.175 & 7.695 \\
\hline
\end{tabular}

compared to other cancer entities, with values ranging from 25 to $43 \%[16,17,29]$.

We also found that the majority of patients with primary brain tumors are in need for referral to psychooncology care. The extent of psychooncologic need correlates with distress, but not with age, sex, Karnofsky performance status (KPS), extend of resection, and current chemotherapy [7], which is in line with our data. In multivariable analysis, a significant positive correlation between psychooncologic need and depression as well as between depression and information need was detected.

Persons in the $\leq 35$ years age group declared no need for referral to psychooncology care. This result may be misleading, as this younger sub-cohort may have a higher portion of lower-grade tumors (grade I/II), which are more prevalent at younger ages [30] and may include long-term survivors of childhood brain tumors. 
However, patients with low-grade tumors, patients aged 51-65 years and patients with a low education level all had less contact with the psychooncologic service teams, comparatively higher levels of depression, and a particularly high need for referral to psychooncology care, raising the hypothesis that access to certain aspects of care is lower in specific patient groups.

In our cross-sectional analysis, we did not find any correlation between disease status and psychooncologic need of the affected patients. However, other publications have shown that the need for referral to psychooncology care is particularly high in close temporal proximity to the time of disease progression or in situations that seem threatening for patients and caregivers [31]. This discordance could be explained by differences between study populations evaluated or by methodologic weaknesses of a cross-sectional investigation.

The psychologic burden borne by family caregivers appears to be particularly high, as relatives have even less psychosocial and social support than patients [32, 33]. Specifically, family caregivers struggle with how to adapt to cognitive changes in the patient and how to manage difficult aspects of the patient's behavior and changing personality, both of which increase over time $[9,10]$. This is reflected by a high and mostly unmet need for referral to psychooncology care for family caregivers in our analysis. Higher values for unmet needs are associated with higher distress levels in cross-sectional analysis [34].

More than a third of the respondents in the current study had a clinically relevant major depression. Other authors have described slightly lower rates for several tumor entities [35]. Therefore, depression in patients with primary brain tumors seems to be above the expected average of all cancer patients. Family caregivers usually rate the level of depression higher than the patients themselves, and are also more reliable than patients in reporting objective behavioral symptoms of depression [36]. Therefore, future studies should not only use self-assessment inventories to evaluate depression, but also family caregiver inventories.

Information need was high and partially unfulfilled in our study population. As also observed in similar studies, brain cancer patients often feel underinformed in early stages of their disease [8]. These observations indicate that communication of diagnosis, treatment, and prognosis should be adapted to patients' personal needs [37].

Multivariable corrections were used in the present study to minimize possible confounding by known brain tumor-related prognostic factors [38] as well as additional tumor- and patient-specific factors that may influence psychooncologic need and depression. The correlation of psychooncologic need with information need and of depression with information need remained statistically significant in multivariable analysis. Therefore, the need for referral to psychooncology care is likely enhanced by a high rate of depression.

Several limitations of this work deserve mention. The survey was performed as a single-center study and at a specific cut-off day, implying that the time point was chosen independently of the specific follow-up status of patients. The patient population was therefore mixed, including both newly diagnosed and relapsed patients, and chronologic sequences could thus only be evaluated in a cross-sectional manner. Furthermore, regarding causality, it is unclear whether higher depression scores induce psychooncologic need or whether unmet psychooncologic need leads to depression. It is also unclear whether a high and unmet information need may induce psychooncologic need and depression. Additional research is needed to explore these aspects further.

\section{Conclusions}

Our results imply that referral to psychooncology care represents a supportive therapy requirement in patients with brain tumors. We show that patients' psychooncologic need and depression burden correlate strongly with counselling and information need. Considering these results, we hypothesize that adequate and repeated information regarding treatment as well as thorough psychooncologic screening and treatment of depression in patients and relatives alike are mandatory for adequate supportive therapy. Indeed, as also shown by others, referral to psychooncology care, sufficient time for face-to-face-meetings, and repeated surveys for patients and relatives are highly relevant for the therapeutic environment. Therefore, we propose that feasible and cost-effective supportive structures should be implemented for the patients and family caregivers who are most in need of them.

\section{Supplementary information}

Supplementary information accompanies this paper at https://doi.org/10. 1186/s40359-020-00460-y.

\footnotetext{
Additional file 1. CONSORT diagram. Five hundred twenty-two patients entered the study, of these 78 were diseased at the timepoint of the acquisition of the questionnaires. Therefore, 444 patients and their relatives were approached; $50.7 \%$ of these responded, with a ratio of $35.4 \%$ of the total population with a valid informed consent.
}

Additional file 2. Distribution of psychooncologic need of patients and family caregivers. A2a: Relative distribution of patients and relatives over the individual scores of the HSI. A2b: Differences in psychooncologic need in between patients and caregivers. Caregivers have significantly higher unmet need in two of the domains in comparison to patients. Psychoooncologic need was derived from Hornheider Screening Instrument, HIS.

Additional file 3. Patients' need for referral to psychooncology care in relation to patient age, WHO grade and education level. A3a: Patients' need for referral to psychooncology care depending on age. A3b: 
Patients' need for referral to psychooncology care depending on diagnosis. A3c: Patients' need for referral to psychooncology care depending on education level. The mean score for all items was derived from Hornheider Screening Instrument, HIS.

Additional file 4. Patient characteristics according to psychooncologic need. Absolute and relative distributions of demographic factors, tumorrelated factors, information levels and depression score according to psychooncologic need yes vs no derived from Hornheider Screening Instrument, HSI. N = $160 \mathrm{HSI}$ scores were collected; missing scores were excluded from the analysis; significant levels are shown in bold.

Additional file 5. Depression level of patients and family caregivers. Depression was evaluated with the PHQ-9 instrument and is depicted as absolute numbers of patients and caregivers in groups for no, minimal, mild, moderate and severe depression. The portion of mild to severe depressed patients or caregivers did not significantly differ between patients (65.0\%) and caregivers (66.9\%).

Additional file 6. Depression level in relation to age, WHO grade and education level. Depression was evaluated with the PHQ-9 instrument. A6a: Mean PHQ-9 score for depression depending on age. A6b: Mean PHQ-9 score for depression depending on WHO grade. A6c: Mean PHQ-9 score for depression depending on education level. The depression level is depicted as mean PHQ-9 score for all items.

Additional file 7. Patient characteristics according to depression level. Absolute and relative distributions of demographic factors, tumor-related factors, information levels and psychooncologic need in relation to depression level $5+$ vs. 0-4 derived form PHQ-9 score are shown. $N=160$ PHQ-9 scores were collected; missing scores were excluded from the analysis; significant levels are shown in bold.

Additional file 8. Patient characteristics according to information need. Absolute and relative distributions of demographic factors, tumor-related factors, information levels and depression level in relation to current information need are shown. Information need is depicted as informed vs. not informed; $N=172$ information need questionnaires were collected; missing scores were excluded from the analysis; significant levels are shown in bold.

Additional file 9. Patient questionnaire.

Additional file 10. Caregivers questionnaire.

\section{Abbreviations}

CNS: Central Nervous System; Cl: Confidence Interval; HSI: Hornheider Screening Instrument; KPS: Karnofsky Performance Status; OR: Odd's Ratio PHQ: Patient Health Questionnaire; WHO: World Health Organisation

\section{Acknowledgements}

We thank all patients and their relatives who participated in the survey. This work was performed in the framework of the Regensburg Brain Tumor Center (Zentrum fuer Hirntumoren, ZHT; https://www.ukr.de/zentren/ zentrum-fuer-hirntumoren/index.php). We thank Birgit Hirschmann and Heike Weißwange for excellent technical support of this study.

\section{Authors' contributions}

All authors have read and approved the manuscript. CR: Conceptualization, Data Curation, Formal Analysis, Investigation, Project Administration, Visualization, Writing - Original Draft Preparation, Writing - Review \& Editing MG: Conceptualization, Data Curation, Formal Analysis, Methodology, Software, Supervision, Visualization, Writing - Review \& Editing. KR: Formal Analysis, Investigation, Writing - Original Draft Preparation. KK: Investigation, Visualization, Writing - Review \& Editing. MKS: Conceptualization, Methodology, Supervision. PLS: Conceptualization, Formal Analysis, Methodology, Validation. OK: Conceptualization, Investigation, Validation, MAP: Conceptualization, Investigation, Validation. MJR: Conceptualization, Investigation, Validation. TP: Conceptualization, Investigation, Validation. EB: Investigation, Validation, Visualization, Writing - Original Draft Preparation. MH: Conceptualization, Formal Analysis, Methodology, Validation, Writing Original Draft Preparation, Writing - Review \& Editing. PH: Conceptualization, Formal Analysis, Funding Acquisition, Methodology, Project Administration, Supervision, Validation, Writing - Review \& Editing.

\section{Funding}

The study was funded in part by grants 2009.800.1 and 2009.800.2 of the Wilhelm Sander Foundation, Munich, Germany. Funding included 3 personmonths for $\mathrm{CR}$ to perform aquisition and analysis of data and to draft the paper. The funder did not influence concept or results of this cross-sectional study. Open access funding provided by Projekt DEAL.

\section{Availability of data and materials}

This non-interventional investigation was not registered in a publicity accessible database. The datasets used during the current study are available from the corresponding author on request.

\section{Ethics approval and consent to participate}

Participation was voluntary, and patients and family caregivers could decline to participate. Written informed consent was raised from all patients and family caregivers. The local ethics committee of the University of Regensburg issued a positive vote on the conduct of this study (number 14-101-0291). All procedures were performed according to the ethical standards laid down in the 1964 Declaration of Helsinki and its later amendments.

\section{Consent for publication}

Does not apply.

\section{Competing interests}

The authors declare that they have no competing interests.

\section{Author details}

${ }^{1}$ Department of Neurology and Wilhelm Sander-NeuroOncology Unit, University Hospital Regensburg, Franz-Josef-Strauß-Allee 11,

Universitätsstrasse 84, 93053 Regensburg, Germany. ${ }^{2}$ Tumor Center - Institute for Quality Assurance and Health Services Research, University of Regensburg, Am Biopark 9, 93053 Regensburg, Germany. ${ }^{3}$ Department of Radiotherapy and Radiation Oncology, University Hospital Regensburg, Franz-Josef-Strauß-Allee 11, 93053 Regensburg, Germany. ${ }^{4}$ Department of Neurosurgery, University Hospital Regensburg, Franz-Josef-Strauß-Allee 11, 93053 Regensburg, Germany. ${ }^{5}$ Department of Neuropathology, Regensburg University Hospital, Franz-Josef-Strauß-Allee 11, 93053 Regensburg, Germany. ${ }^{6}$ Department of Internal Medicine III, University Hospital Regensburg, Franz-Josef-Strauß-Allee 11, 93053 Regensburg, Germany. ${ }^{7}$ Department of Neurology 1, NeuroMed Campus, Kepler University Hospital Linz, Wagner-Jauregg-Weg 15, A-4020 Linz, Austria.

Received: 7 January 2020 Accepted: 6 August 2020

Published online: 10 September 2020

\section{References}

1. Ostrom QT, Gittleman H, Fulop J, Liu M, Blanda R, Kromer C, Wolinsky Y, Kruchko C, Barnholtz-Sloan JS. CBTRUS Statistical Report: Primary Brain and Central Nervous System Tumors Diagnosed in the United States in 20082012. Neuro-Oncology. 2015;17(Suppl 4):iv1-iv62.

2. Trad W, Koh ES, Daher M, Bailey A, Kastelan M, Legge D, Fleet M, Simpson GK, Hovey E. Screening for psychological distress in adult primary brain tumor patients and caregivers: considerations for Cancer care coordination. Front Oncol. 2015:5:203.

3. Singer $\mathrm{S}$, Roick J, Danker $\mathrm{H}$, Kortmann RD, Papsdorf K, Taubenheim S, Renovanz M, Jahne K, Meixensberger J. Psychiatric co-morbidity, distress, and use of psycho-social services in adult glioma patients-a prospective study. Acta Neurochir. 2018:160(6):1187-94.

4. Piil K, Jakobsen J, Christensen KB, Juhler M, Guetterman TC, Fetters MD, Jarden M. Needs and preferences among patients with high-grade glioma and their caregivers - a longitudinal mixed methods study. Eur J Cancer Care (Engl). 2018;27(2):e12806.

5. Rooney AG, McNamara S, Mackinnon M, Fraser M, Rampling R, Carson A, Grant R. The frequency, longitudinal course, clinical associations, and causes of emotional distress during primary treatment of cerebral glioma. NeuroOncology. 2013;15(5):635-43.

6. Sanders SL, Bantum EO, Owen JE, Thornton AA, Stanton AL. Supportive care needs in patients with lung cancer. Psychooncology. 2010;19(5):480-9.

7. Renovanz M, Hechtner M, Janko M, Kohlmann K, Coburger J, Nadji-Ohl M, Konig J, Ringel F, Singer S, Hickmann AK. Factors associated with supportive 
care needs in glioma patients in the neuro-oncological outpatient setting. J Neuro-Oncol. 2017;133(3):653-62.

8. Cavers D, Hacking B, Erridge SC, Morris PG, Kendall M, Murray SA. Adjustment and support needs of glioma patients and their relatives: serial interviews. Psychooncology. 2013;22(6):1299-305.

9. Halkett GK, Lobb EA, Shaw T, Sinclair MM, Miller L, Hovey E, Nowak AK Distress and psychological morbidity do not reduce over time in carers of patients with high-grade glioma. Support Care Cancer. 2017;25(3):887-93.

10. Andrewes HE, Drummond KJ, Rosenthal M, Bucknill A, Andrewes DG. Awareness of psychological and relationship problems amongst brain tumour patients and its association with carer distress. Psychooncology. 2013;22(10):2200-5.

11. Applebaum AJ, Buda K, Kryza-Lacombe M, Buthorn JJ, Walker R, Shaffer KM, D'Agostino TA, Diamond EL. Prognostic awareness and communication preferences among caregivers of patients with malignant glioma. Psychooncology. 2018;27(3):817-23.

12. Davison BJ, Goldenberg SL, Gleave ME, Degner LF. Provision of individualized information to men and their partners to facilitate treatment decision making in prostate cancer. Oncol Nurs Forum. 2003;30(1):107-14.

13. Meredith C, Symonds P, Webster L, Lamont D, Pyper E, Gillis CR, Fallowfield L. Information needs of cancer patients in West Scotland: cross sectional survey of patients' views. BMJ. 1996;313(7059):724-6.

14. Fallowfield $\mathrm{L}$, Ford $\mathrm{S}$, Lewis $\mathrm{S}$. No news is not good news: information preferences of patients with cancer. Psychooncology. 1995;4(3):197-202.

15. Baumstarck K, Chinot O, Tabouret E, Farina P, Barrie M, Campello C, Petrirena G, Hamidou Z, Auquier P. Coping strategies and quality of life: a longitudinal study of high-grade glioma patient-caregiver dyads. Health Qual Life Outcomes. 2018;16(1):157.

16. Zabora J, BrintzenhofeSzoc K, Curbow B, Hooker C, Piantadosi S. The prevalence of psychological distress by cancer site. Psychooncology. 2001; 10(1):19-28.

17. Herschbach P, Keller M, Knight L, Brandl T, Huber B, Henrich G, MartenMittag B. Psychological problems of cancer patients: a cancer distress screening with a cancer-specific questionnaire. Br J Cancer. 2004;91 (3):504-11.

18. Faller $\mathrm{H}$, Schuler $\mathrm{M}$, Richard $\mathrm{M}$, Heckl U, Weis J, Kuffner R. Effects of psychooncologic interventions on emotional distress and quality of life in adult patients with cancer: systematic review and meta-analysis. J Clin Oncol. 2013;31(6):782-93

19. Kuchler T, Bestmann B, Rappat S, Henne-Bruns D, Wood-Dauphinee S. Impact of psychotherapeutic support for patients with gastrointestinal cancer undergoing surgery: 10-year survival results of a randomized trial. J Clin Oncol. 2007;25(19):2702-8.

20. Nass SJ, Beaupin LK, Demark-Wahnefried W, Fasciano K, Ganz PA, HayesLattin B, Hudson MM, Nevidjon B, Oeffinger KC, Rechis R, et al. Identifying and addressing the needs of adolescents and young adults with cancer: summary of an Institute of Medicine workshop. Oncologist. 2015;20(2):186-95.

21. DeRouen MC, Smith AW, Tao L, Bellizzi KM, Lynch CF, Parsons HM, Kent EE, Keegan TH, Group AHSC. Cancer-related information needs and cancer's impact on control over life influence health-related quality of life among adolescents and young adults with cancer. Psychooncology. 2015;24(9):1104-15.

22. Rood JAJ, Nauta IH, Witte BI, Stam F, van Zuuren FJ, Manenschijn A, Huijgens PC, Verdonck-de Leeuw IM, Zweegman S. Shared decision-making and providing information among newly diagnosed patients with hematological malignancies and their informal caregivers: not "one-size-fitsall". Psychooncology. 2017;26(12):2040-7.

23. Tilkorn M, Mawick R, Sommerfeld S, Strittmatter G. Quality of life of patients with malignant facial and skin tumors--development of a questionnaire and initial findings of a study. Rehabilitation (Stuttg). 1990;29(2):134-9.

24. Schaeffeler N, Pfeiffer K, Ringwald J, Brucker S, Wallwiener M, Zipfel S, Teufel M. Assessing the need for psychooncological support: screening instruments in combination with patients' subjective evaluation may define psychooncological pathways. Psychooncology. 2015;24(12):1784-91.

25. Kroenke K, Spitzer RL, Williams JB. The PHQ-9: validity of a brief depression severity measure. J Gen Intern Med. 2001;16(9):606-13.

26. Lowe B, Kroenke K, Herzog W, Grafe K. Measuring depression outcome with a brief self-report instrument: sensitivity to change of the patient health questionnaire (PHQ-9). J Affect Disord. 2004;81(1):61-6.

27. Reinert C, Kremmler L, Burock S, Bogdahn U, Wick W, Gleiter CH, Koller M, Hau P. Quantitative and qualitative analysis of study-related patient information sheets in randomised neuro-oncology phase III-trials. Eur J Cancer. 2014;50(1):150-8.
28. Gorlia T, Wu W, Wang M, Baumert BG, Mehta M, Buckner JC, Shaw E, Brown P, Stupp R, Galanis E, et al. New validated prognostic models and prognostic calculators in patients with low-grade gliomas diagnosed by central pathology review: a pooled analysis of EORTC/RTOG/NCCTG phase III clinical trials. Neuro-Oncology. 2013;15(11):1568-79.

29. Ford E, Catt S, Chalmers A, Fallowfield L. Systematic review of supportive care needs in patients with primary malignant brain tumors. NeuroOncology. 2012;14(4):392-404.

30. Ostrom QT, Gittleman H, XU J, Kromer C, Wolinsky Y, Kruchko C, BarnholtzSloan JS. CBTRUS Statistical Report: Primary Brain and Other Central Nervous System Tumors Diagnosed in the United States in 2009-2013. NeuroOncology. 2016;18(suppl_5):v1-v75.

31. Strang S, Strang P, Ternestedt BM. Existential support in brain tumour patients and their spouses. Support Care Cancer. 2001;9(8):625-33.

32. Nijboer C, Tempelaar R, Triemstra M, van den Bos GA, Sanderman R. The role of social and psychologic resources in caregiving of cancer patients. Cancer. 2001;91(5):1029-39.

33. Edwards B, Clarke V. The psychological impact of a cancer diagnosis on families: the influence of family functioning and patients' illness characteristics on depression and anxiety. Psychooncology. 2004;13(8):562-76.

34. Halkett GKB, Lobb EA, Shaw T, Sinclair MM, Miller L, Hovey E, Nowak AK. Do carer's levels of unmet needs change over time when caring for patients diagnosed with high-grade glioma and how are these needs correlated with distress? Support Care Cancer. 2018;26(1):275-86.

35. Singer S, Szalai C, Briest S, Brown A, Dietz A, Einenkel J, Jonas S, Konnopka A, Papsdorf K, Langanke D, et al. Co-morbid mental health conditions in cancer patients at working age--prevalence, risk profiles, and care uptake. Psychooncology. 2013;22(10):2291-7.

36. Rooney AG, McNamara S, Mackinnon M, Fraser M, Rampling R, Carson A, Grant R. Screening for major depressive disorder in adults with glioma using the PHQ-9: a comparison of patient versus proxy reports. J NeuroOncol. 2013;113(1):49-55.

37. Lobb EA, Halkett GK, Nowak AK. Patient and caregiver perceptions of communication of prognosis in high grade glioma. J Neuro-Oncol. 2011; 104(1):315-22.

38. Gorlia T, van den Bent MJ, Hegi ME, Mirimanoff RO, Weller M, Cairncross JG, Eisenhauer E, Belanger K, Brandes AA, Allgeier A, et al. Nomograms for predicting survival of patients with newly diagnosed glioblastoma: prognostic factor analysis of EORTC and NCIC trial 26981-22981/CE.3. Lancet Oncol. 2008;9(1):29-38.

\section{Publisher's Note}

Springer Nature remains neutral with regard to jurisdictional claims in published maps and institutional affiliations.

Ready to submit your research? Choose BMC and benefit from

- fast, convenient online submission

- thorough peer review by experienced researchers in your field

- rapid publication on acceptance

- support for research data, including large and complex data types

- gold Open Access which fosters wider collaboration and increased citations

- maximum visibility for your research: over $100 \mathrm{M}$ website views per year

At $\mathrm{BMC}$, research is always in progress.

Learn more biomedcentral.com/submission 